\title{
Humour styles, personality and psychological well-being: What's humour got to do with it?
}

\author{
Willibald Ruch \\ Sonja Heintz \\ University of Zurich, Switzerland
}

\begin{abstract}
The Humor Styles Questionnaire (HSQ) by Martin et al. (2003) measures four humour styles, namely affiliative, self-enhancing, aggressive and self-defeating. In contrast to former humour instruments, the HSQ has strong relations to various measures of psychological wellbeing. However, its incremental validity in relation to basic personality traits has not been sufficiently studied. Two studies analysed how much unique variance the HSQ contributed to predicting psychological well-being over and above personality. While the affiliative, selfenhancing and self-defeating humour style were potent predictors of well-being in Study 1, the results also indicated that these humour styles had small effects when personality was controlled for. Study 2 tested a possible explanation for these findings, namely that the context (i.e., non-humorous components) of the HSQ items dominates their humour-specific content. Two questionnaires were utilised to separate context and humour components in the $H S Q$. Results showed that (a) the HSQ contributed little in predicting personality and psychological well-being once context was controlled for, and that (b) the humour component of each HSQ scale correlated highly with other humour instruments and neither of them were detrimental or maladaptive in terms of psychological well-being. Thus, these two studies showed a low incremental validity of humour styles in predicting psychological well-being beyond personality and hint to a limited role that humour plays in the these relationships. Overall, the humour components of the HSQ rather resemble those of other self-report measures and mainly comprise humour appreciation and humour production in everyday life.
\end{abstract}

Keywords: HSQ; humour styles; incremental validity; personality; psychological well-being. 


\section{Introduction}

Psychological humour research often employs a one-dimensional and trait-like concept of the sense of humour, regarding humour as stable across time and situations. Both theory (e.g., superiority theories of humour; humour as a mature defence mechanism, Freud, 1905) and research early focused on the relation of humour and psychosocial and physical well-being. However, empirical findings only showed weak and inconsistent relations of humour with well-being (for reviews, see Martin, 2001, 2007). The current studies add to this literature by examining the incremental validity of the Humor Styles Questionnaire (HSQ; Martin, PuhlikDoris, Larsen, Gray \& Weir, 2003) beyond personality in predicting psychological well-being and by elucidating the role that humour plays in these relationships.

The HSQ was developed as a comprehensive self-report measure of everyday functions of humour, especially those relevant to psychosocial well-being. Martin et al. (2003) postulated two goals of using humour - to enhance oneself vs. to enhance one's relationships with others - as well as two ways of using humour to achieve these goals - in a benign vs. in a detrimental way. This classification resulted in four different humour styles, i.e., affiliative (enhancing relationships/benign for self), self-enhancing (enhancing self/benign for others), aggressive (enhancing self/detrimental for others) and self-defeating (enhancing relationships/detrimental for self).

The affiliative and self-enhancing humour styles are similar to former conceptualizations of humour (evidenced by medium to high correlations with other selfreport humour instruments; Martin et al., 2003). They both entail humour production, a propensity to laugh and to be amused/cheerful. However, the affiliative humour style is mainly to be displayed when being with others, while self-enhancing is mainly to be shown when being alone. In addition, the self-enhancing humour style entails a coping element (as it was in part derived from the Coping Humour Scale or CHS; Martin \& Lefcourt, 1983), which is reflected in statements comprising problems or a negative mood state.

The aggressive and self-defeating humour styles occur in social situations, entail humour production and share an impulsive element (like going overboard or not being able to contain oneself). The aggressive humour style is supposed to be mocking, criticising and offensive and comprises a lack of respect for the feelings of others. The self-defeating humour style mainly refers to making fun of oneself or having others laugh at oneself more than one feels comfortable with. As these two "negative" styles were only partly measured by former humour instruments, Martin et al. (2003) concluded that the HSQ is a more comprehensive measure of everyday functions of humour than former instruments.

Martin et al. (2003) reported good internal consistencies (Cronbach's alpha) of the four scales and also supported the construct validity of the HSQ with correlations to various questionnaires. Convergent validity of the affiliative and self-enhancing humour style was shown with other humour questionnaires. Consistent with the proposed relation of humour and well-being, the two benign humour styles correlated negatively with anxiety and depression, while the self-defeating style correlated positively with them. Well-being and optimism showed the highest relations with the self-enhancing humour style, which is in line with results of the CHS (Martin, 1996). In contrast, the aggressive humour style was uncorrelated with well-being, but showed positive relations to aggression and hostility. Correlations with the personality traits of the five-factor model (FFM) were also in the expected directions, with the two benign styles relating positively to extraversion and 


\section{European Journal of Humour Research1(4)}

openness (and self-enhancing in addition to emotional stability and agreeableness), and the two detrimental styles relating negatively to emotional stability, agreeableness and conscientiousness. This result was novel as most former humour measures related positively to extraversion only (Köhler \& Ruch, 1996; Martin et al., 2003). Overall, the variance explained by the four humour styles in the measures of personality $\left(R^{2}=12-37\right.$ per cent $)$ and well-being, mood and social relationships $\left(R^{2}=11-37\right.$ per cent $)$ showed medium to large effect sizes.

These relations of the humour styles with well-being and personality were replicated in numerous studies (e.g., Edwards \& Martin, 2010; Frewen, Brinker, Martin \& Dozois, 2008; Galloway, 2010; Kuiper, Grimshaw, Leite \& Kirsh, 2004; Páez, Mendiburo \& MartínezSanchez, 2012; Saroglou \& Scariot, 2002). Depression went along with lower affiliative and self-enhancing humour styles and a higher self-defeating humour style, while self-esteem and well-being showed the opposite correlation patterns. Optimism went along with a higher selfenhancing humour style, and life satisfaction additionally correlated positively with the affiliative humour style. Regarding personality, extraversion and openness were related to higher affiliative and self-enhancing humour styles, and extraversion also to a higher aggressive humour style. Neuroticism correlated negatively with the affiliative and selfenhancing and positively with the self-defeating humour style. Agreeableness went along with higher self-enhancing and lower aggressive humour styles. Conscientiousness correlated negatively with the aggressive and self-defeating humour styles. Thus, the HSQ consistently related to psychological well-being and personality.

This raises the question why the HSQ shows these relationships, while other self-report measures of humour do not. Is it due to the multidimensionality and inclusion of "negative" aspects of humour? Or might it be caused by the overlap with personality or other contexts that inflate the correlation of the HSQ with well-being? A further question is which role the humour components of the HSQ play in these findings. For example, is it already detrimental to well-being when one makes too much fun about oneself (the humour component of selfdefeating), or is it rather the negative evaluation of this humorous behaviour entailed in this humour style? To clarify the relation of the humour styles with well-being and personality, several points require further attention.

For a measure to be practical relevance, not only predictive validity needs to be established (best in longitudinal studies and/or in experimental settings), but the measure also needs to have incremental validity over and above well-established measures. Kuiper and Harris (2009) tested if the HSQ predicts illness attitudes beyond negative affect. They found that the effect of the humour styles vanished when negative affect was controlled for and concluded that "[...] this pattern clearly highlights the importance of considering other relevant individual difference variables, such as negative affect, when attempting to ascertain the specific role of humour measures" (p. 12). Similarly, the four humour styles should be able to predict psychological well-being when personality is controlled for.

Personality (frequently conceptualized within the FFM; e.g., Digman, 1990) is a suitable standard of comparison for two reasons. Firstly, the personality traits of the FFM have consistently been found to have medium to strong relations with various measures of well-being (e.g., DeNeve \& Cooper, 1998; Robins, Tracy, Trzesniewski, Potter \& Gosling, 2001; Sharpe, Martin \& Roth, 2011). Secondly, the HSQ has established medium to strong relations with personality (e.g., Martin et al., 2003; Galloway, 2010; Páez et al., 2013). In fact, the highest correlations reported by Martin et al. (2003) for the aggressive $(r=-.59$ with agreeableness) and self-defeating humour style ( $r=.38$ with hostility) were not referring to 


\section{European Journal of Humour Research1(4)}

humour. This either means that these two scales measure novel aspects of humour (as Martin et al. interpreted their findings) or that they are not specific to humour, but also include personality or context elements (e.g., social settings, behaviours and attitudes) that are less related to humour itself.

A study that employed personality measures to investigate the incremental validity of the HSQ with regards to well-being showed small effect sizes of the humour styles over and above personality. Jovanovic (2011) found that the self-enhancing humour style had incremental validity in predicting affective well-being and life satisfaction over and above neuroticism and extraversion, respectively $(\beta s<.16, p s<.05)$. In addition, the affiliative humour style predicted affective well-being over and above neuroticism $(\beta=.20, p<.001)$. However, to investigate the incremental validity of the humour styles in comparison to personality comprehensively, all FFM personality traits have to be considered. It would also be desirable to study more components of psychological well-being apart from subjective well-being (like optimism and self-esteem).

In addition, the role of humour in the HSQ warrants further investigation. As outlined above, the two "detrimental" humour styles showed only a small overlap with other humour measures. This could be due to the measurement of novel aspects of humour or to a lack of validity of these scales. Thus, it remains unsettled what role humour actually plays in the relations of these humour styles to personality and well-being, and to what extent humour can be interpreted as detrimental and maladaptive. Specifically, aggressive humour shares many components with affiliative humour (as both entail humour production in social contexts), and the self-defeating humour style bears a striking resemblance to the long-acknowledged concept of "laughing at yourself", which is a core component of the sense of humour and in terms of well-being - an adaptive form of humour (e.g., McGhee, 1996). To solve these apparent contradictions and to clarify the role of humour in the HSQ, a more detailed examination of the humour components of the humour styles is needed.

This paper comprises two studies that aim at shedding more light on the relationship between the HSQ, personality and psychological well-being and on the role of humour and context in these relationships. Study 1 examines the incremental validity of the HSQ in predicting well-being (including life satisfaction, positive and negative affect, self-esteem, optimism and depression) beyond the FFM personality traits. A unique effect of the humour styles beyond personality would underscore the practical importance of the HSQ in predicting psychological well-being. We expected small incremental validities in line with former findings (Jovanovic, 2011). Study 2 aims at replicating the main findings from Study 1 and at separating the effects of the context (e.g., social setting, mood state) and the humour-related content in the HSQ using two questionnaires (Ruch \& Heintz, 2014). This allows for testing (a) the incremental validity of the HSQ in predicting well-being beyond the context, and (b) the relation of the HSQ humour components with personality, psychological well-being and other humour measures. 


\section{Study 1}

\subsection{Materials and methods}

\subsubsection{Participants}

A total of 162 participants (24 per cent men) with a median age of $24(M=27.33, S D=9.37)$ ranging from 17 to 64 years provided valid responses in this study. Most participants were Swiss (61 per cent), German (29 per cent) and from several other nations. Overall, they were well-educated, with 47 per cent being college or university students, 28 per cent having passed tertiary education, 17 per cent having A-levels and six per cent having an apprenticeship.

\subsubsection{Instruments}

Humor Styles Questionnaire (HSQ; Martin et al., 2003). The HSQ consists of 32 items measuring four humour styles. Sample items are "I enjoy making people laugh" (affiliative), "Even when I'm by myself, I'm often amused by the absurdities of life" (self-enhancing), "If I don't like someone, I often use humor or teasing to put them down" (aggressive), and "I let people laugh at me or make fun at my expense more than I should" (self-defeating). The instrument employs a seven-point Likert scale from "totally disagree" (1) to "totally agree" (7). Internal consistencies (Cronbach's alpha) ranged from .77 to .81 .

Big Five Inventory (BFI; John, Donahue \& Kentle, 1991). The BFI measures the FFM personality dimensions with 44 items (with 8 to 10 items per trait). Sample items are "I see myself as someone who is talkative" (extraversion), "I see myself as someone who is depressed, blue" (neuroticism), "I see myself as someone who has an active imagination" (openness), "I see myself as someone who is helpful and unselfish with others" (agreeableness), and "I see myself as someone who does a thorough job" (conscientiousness). The instrument employs a five-point Likert scale from "disagree strongly" (1) to "agree strongly" (5). Cronbach's alpha typically ranges from .75 to .90.

Satisfaction With Life Scale (SWLS; Diener, Emmons, Larsen \& Griffin, 1985). The five-item SWLS measures life satisfaction (e.g., "I am satisfied with my life"). The instrument employs a seven-point Likert scale from "strongly disagree" (1) to "strongly agree" (7). Cronbach's alpha was .87 (in the current study .88).

Positive and Negative Affect Schedule (PANAS; Watson, Clark \& Tellegen, 1988). The PANAS consists of 20 adjectives, with 10 adjectives each measuring positive affect (e.g., "enthusiastic") and negative affect (e.g., "nervous"). The instrument employs a five-point Likert scale from "very slightly or not at all" (1) to "extremely" (5) and was used with the general temporal instruction to measure trait affect. Cronbach's alpha was .88 and .87 (in the current study .85 and .83).

Rosenberg Self-Esteem Scale (RSES; Rosenberg, 1965). The 10-item RSES measures self-esteem (e.g., "I am able to do things as well as most other people"). The instrument employs a four-point Likert scale from "strongly disagree" (1) to "strongly agree" (4). Cronbach's alpha of a revised German version (von Collani \& Herzberg, 2003) ranged from .84 to .85 (in the current study .92).

Life Orientation Test-Revised (LOT-R; Scheier, Carver \& Bridges, 1994). The LOT-R consists of 10 items (including four filler items), with three items each of an optimistic (e.g., "I'm always optimistic about my future") and pessimistic nature (e.g., "If something can go wrong for me, it will"). Recoding the pessimism items yields a global scale of optimism. The 


\section{European Journal of Humour Research1(4)}

instrument employs a five-point Likert scale from "strongly disagree" (1) to "strongly agree" (5). Cronbach's alpha was .78 (in the current study .85).

Center for Epidemiologic Studies Depression Scale (CES-D Scale; Radloff, 1977). The CES-D Scale consists of 20 items and measures depression in the general population (e.g., "During the past week, I felt lonely"). The instrument employs a four-point Likert scale from "Rarely or none of the time [less than 1 day]" (1) to "Most or all of the time [5-7 days]" (4). Cronbach's alpha was .84 to .90 (in the current study .92).

\subsubsection{Procedure}

The data were collected in an online survey. Participants were recruited via several means, including mailing lists of the University of Zurich, social media platforms and bulletins at the University of Zurich and the Swiss Federal Institute of Technology Zurich. Participants were offered a personalized feedback and/or course credit in psychology for their participation.

\subsubsection{Data analysis}

Pearson correlations were used to determine the relations among the HSQ, personality and well-being. Hierarchical multiple regression analyses were conducted to determine the amount of incremental validity of the HSQ over and above personality in predicting psychological well-being.

\subsection{Results}

Table 1 shows the means, standard deviations, intercorrelations and internal consistencies (Cronbach's alpha) of the HSQ and personality as well as their correlations with the six measures of psychological well-being.

Table 1. Means, standard deviations, intercorrelations, and internal consistencies (Cronbach's alpha) of the Humor Styles Questionnaire (HSQ) and the Big Five Inventory (BFI) as well as their correlations with the psychological well-being scales.

\begin{tabular}{|c|c|c|c|c|c|c|c|c|c|c|c|}
\hline Scales & $M$ & $S D$ & $(1)$ & $(2)$ & (3) & $(4)$ & $(5)$ & $(6)$ & $(7)$ & $(8)$ & (9) \\
\hline \multicolumn{12}{|l|}{ HSQ } \\
\hline (1) Affiliative & 43.70 & 8.41 & .89 & & & & & & & & \\
\hline (2) Self-enhancing & 36.14 & 8.97 & $.51 *$ & .89 & & & & & & & \\
\hline (3) Aggressive & 26.75 & 7.36 & $.34 *$ & .14 & .75 & & & & & & \\
\hline (4) Self-defeating & 25.02 & 9.64 & .10 & .11 & .16 & .90 & & & & & \\
\hline \multicolumn{12}{|l|}{ BFI } \\
\hline (5) Extraversion & 3.48 & 0.81 & $.60 *$ & $.40 *$ & $.26^{*}$ & -.10 & .88 & & & & \\
\hline (6) Agreeableness & 3.77 & 0.57 & .21 & .25 & $-.28 *$ & -.01 & .23 & .74 & & & \\
\hline (7) Conscientious. & 3.56 & 0.66 & .20 & .03 & -.25 & -.09 & $.35^{*}$ & .21 & .75 & & \\
\hline (8) Neuroticism & 2.85 & 0.84 & $-.30 *$ & $-.50 *$ & -.12 & $.26^{*}$ & $-.44 *$ & -.24 & -.07 & .87 & \\
\hline (9) Openness & 4.03 & 0.54 & .20 & .21 & -.01 & .01 & .23 & -.02 & .12 & -.08 & .73 \\
\hline \multicolumn{12}{|l|}{ Well-being } \\
\hline Life satisfaction & 4.76 & 1.31 & .24 & $.37 *$ & .08 & $-.30 *$ & $.48^{*}$ & .21 & .23 & $-.59 *$ & .05 \\
\hline Positive affect & 34.87 & 6.14 & $.40 *$ & $.40 *$ & .21 & -.21 & $.72 *$ & .11 & $.33 *$ & $-.43 *$ & .22 \\
\hline Negative affect & 19.89 & 6.15 & -.20 & $-.34 *$ & -.01 & $.32 *$ & $-.37 *$ & -.22 & -.23 & $.63^{*}$ & -.07 \\
\hline Self-esteem & 32.85 & 6.25 & $.34 *$ & $.40^{*}$ & .07 & $-.32 *$ & $.54 *$ & .24 & $.30 *$ & $-.63 *$ & .08 \\
\hline Optimism & 22.28 & 4.67 & $.32 *$ & $.45^{*}$ & -.02 & $-.28 *$ & $.50 *$ & $.33 *$ & .25 & $-.63 *$ & .14 \\
\hline Depression & 33.60 & 10.38 & $-.32 *$ & $-.40 *$ & -.10 & .25 & $-.43 *$ & $-.29 *$ & -.20 & $.58 *$ & -.06 \\
\hline
\end{tabular}

Note. $N=162$. Conscientious. $=$ Conscientiousness; Cronbach's alpha in italics.

$* p<.001$ (adjusted level of significance due to alpha error accumulation). 


\section{European Journal of Humour Research1(4)}

Table 1 shows that the intercorrelations among the HSQ and personality were similar to those found in former studies: The affiliative and self-enhancing humour styles correlated positively with extraversion and negatively with neuroticism (medium to large effects). Furthermore, the aggressive humour style correlated positively with extraversion and negatively with agreeableness, while self-defeating correlated positively with neuroticism (small to medium effects).

Both personality (except for openness) and humour styles (except for aggressive) showed significant relations with the well-being measures. The affiliative and self-enhancing humour styles correlated positively with positive affect, self-esteem and optimism, and negatively with negative affect and depression (medium effects). Self-enhancing also correlated positively with life satisfaction. In addition, the self-defeating humour style showed positive relations to negative affect and negative relations to life satisfaction, self-esteem and optimism. With respect to personality, extraversion correlated with higher well-being and neuroticism with lower well-being in all measures (medium to large effects). Moreover, agreeableness correlated positively with optimism and negatively with depression, while conscientiousness correlated positively with positive affect and self-esteem (medium effects).

\subsubsection{Incremental validity of the HSQ beyond personality}

To examine the incremental validity of the HSQ beyond personality, Table 2 shows the hierarchical multiple regression analyses predicting various measures of well-being with the FFM personality traits in step 1 (enter method) and the four scales of the HSQ in step 2 (stepwise method).

Table 2 shows that personality explained between 40 per cent (depression) and 55 per cent (positive affect) of the variance in the well-being measures. The four humour styles showed a significant incremental validity of two to three per cent in life satisfaction, negative affect, self-esteem and optimism (and no incremental effect for positive affect and depression). Regarding the beta weights, the self-defeating humour style remained a significant negative predictor of life satisfaction, self-esteem and optimism and a positive predictor of negative affect. The self-enhancing humour style was a significant positive predictor beyond personality for optimism. It is noteworthy that the inverse analysis (incremental validity of the FFM beyond the four humour styles) yielded large effects $(.15<$ $\left.\Delta R^{2}<.28\right)$.

\subsection{Discussion}

The zero-order correlations showed that the four HSQ humour styles had substantial relations with the six measures of well-being (life satisfaction, positive and negative affect, self-esteem, optimism and depression). When controlling for personality in the hierarchical regression analyses, they had either no or a small incremental effect of two to three per cent of unique variance in explaining the measures of well-being. Thus, the present study adds to the validity of the HSQ by replicating the often found medium to large effects of the humour styles in predicting well-being in a new country, Switzerland. However, the study also shows that these effects were largely attributable to personality. Nevertheless, the self-defeating and to a lesser extent the self-enhancing humour style still remained significant predictors of some wellbeing measures when personality was accounted for. These findings had similar effects sizes as the former study (Jovanovic, 2011), yet the self-defeating humour style rather than the selfenhancing one explained unique variance. 


\section{European Journal of Humour Research1(4)}

This pattern of results could have at least two explanations: Personality might underlie the humour styles and thus share most of the relevant variance in predicting well-being with it. For example, extraversion scales can contain statements of liking to tell jokes and funny stories (e.g, item 55 of the Eysenck Personality Questionnaire - Revised; Eysenck, Eysenck \& Barrett, 1985), which is a defining feature of the affiliative humour style. Hence adding the affiliative humour style in predicting a measure of psychological well-being would not add any new information beyond extraversion. This does however not suggest that humour styles have no validity in predicting psychological well-being; rather they have little practical relevance, as they add little beyond already established measures.

Alternatively, these findings might be explained by the fact that contextual features of the items, and not only content, generate variance, and maybe some of the correlations with external variables (e.g., personality and well-being) are caused by the context. Martin et al. (2003) wrote that they "[...] attempted to follow Jackson's recommendations to generate relatively short, unambiguous items with high content saturation, including items tapping negative as well as positive instances of each construct" (p. 55). Nevertheless, in the final HSQ many of the items contain context features, such as the social setting (e.g., being with friends, family or alone), intentions (e.g., to mask one's feelings or to put others down) or moods (e.g., being depressed or sad). These contexts naturally overlap with both personality and well-being measures and might artificially inflate the relationships between the humour styles and well-being. It seems inevitable that sometimes context and content are confounded; e.g., for affiliative humour (i.e., telling jokes, entertaining) an audience is needed, which limits the possible variations of contexts and always involves contexts favouring extraverts. By contrast, in the items of the self-enhancing humour style, the individuals are often alone and/or not feeling well. Hence the context already produces variance, as we differ in how often we are in company and how much we like to talk to others or entertain them (even if not using humour). Thus, the assumption is that the context of the items (in which we would or would not act humorously) already co-determines the answer. 


\section{European Journal of Humour Research1(4)}

Table 2. Hierarchical multiple regression analyses predicting various measures of psychological well-being with the Big Five Inventory (BFI) personality traits in step 1 (enter method) and the four scales of the Humor Styles Questionnaire (HSQ) in step 2 (stepwise method, only final solution reported).

\begin{tabular}{|c|c|c|c|c|c|c|c|c|c|c|c|c|}
\hline \multirow[b]{2}{*}{ Predictor } & \multicolumn{2}{|c|}{ Life satisfaction } & \multicolumn{2}{|c|}{ Positive affect } & \multicolumn{2}{|c|}{ Negative affect } & \multicolumn{2}{|c|}{ Self-esteem } & \multicolumn{2}{|c|}{ Optimism } & \multicolumn{2}{|c|}{ Depression } \\
\hline & $\Delta R^{2}$ & $\beta$ & $\Delta R^{2}$ & $\beta$ & $\Delta R^{2}$ & $\beta$ & $\Delta R^{2}$ & $\beta$ & $\Delta R^{2}$ & $\beta$ & $\Delta R^{2}$ & $\beta$ \\
\hline Step 1 & $.42 * * *$ & & $.55 * * *$ & & $.44 * * *$ & & $.51 * * *$ & & $.50 * * *$ & & $.40 * * *$ & \\
\hline BFI E & & $.24 * *$ & & $.61 * * *$ & & -.04 & & $.27 * * *$ & & $.20 * *$ & & $-.17 *$ \\
\hline BFI A & & .01 & & -.10 & & -.04 & & .03 & & $.15^{*}$ & & -.12 \\
\hline BFI C & & .12 & & $.12 *$ & & $-.17 *$ & & .17 & & .11 & & -.09 \\
\hline BFI N & & $-.48 * * *$ & & $-.17 * *$ & & $.60 * * *$ & & $-.50 * * *$ & & $-.50 * * *$ & & $.48^{* * *}$ \\
\hline BFI O & & -.06 & & .05 & & .00 & & -.04 & & .04 & & .03 \\
\hline Step 2 & $.02 *$ & & - & & $.02 *$ & & $.02 * *$ & & $.03 * *$ & & - & \\
\hline HSQ AF & & - & & - & & - & & - & & - & & - \\
\hline HSQ SE & & - & & - & & - & & - & & $.17^{*}$ & & - \\
\hline HSQ AG & & - & & - & & - & & - & & - & & - \\
\hline HSQ SD & & $-.16^{*}$ & & - & & $.16^{*}$ & & $-.16 * *$ & & $-.17 * *$ & & - \\
\hline Total $R^{2}$ & $.44 * * *$ & 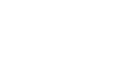 & $.55^{* * *}$ & 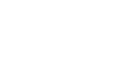 & $.46 * * *$ & & $.54 * * *$ & & $.53 * * *$ & & $.40 * * *$ & \\
\hline
\end{tabular}


To investigate this latter explanation, a method study is needed that empirically tests the amount of variance the content and the context parts generate. Two questions need to be answered. First, is a clear-cut distinction into content and context possible? Here we acknowledge that while no sharp distinction will be possible in every single case, we are optimistic that overall a valid separation will be obtained. Next we need to discuss whether content and context are homogeneous categories. Regarding the contents, several distinct but empirically correlated humour behaviours are expected to make up a single humour style. Regarding the context (i.e., the non-humorous elements of an item), we see that it is comprised of variations in a multitude of factors, such as physical and social situations, situational and organismic antecedents and consequences. For now, we have to accept that this is a very heterogeneous category whose impact we want to examine as a whole (notwithstanding that some of these factors reflect wanted and others unwanted sources of variance).

One possibility to operationalize these ideas is to rephrase the HSQ items to either contain their content (i.e., humour-related words or phrases) or context components (i.e., non humour-related words or phrases). This procedure would not only allow to empirically test the amount of variance these parts generate, but also to examine which parts of the items are relevant for the relationship between the humour styles and other instruments. Following this rationale, Ruch and Heintz (2014) developed two new scales that are HSQ derivatives. To generate a "context" form they changed the items minimally to eliminate the humour elements (substituting it by something similar but non-humorous). To generate a "humour" form, they stripped of everything that goes beyond the humour content (be it situational conditions, thoughts or feelings when showing the humour behaviour or evaluations of the behaviour).

For example, the HSQ self-defeating item "I let people laugh at me or make fun at my expense more than I should" can be decomposed into its humour part ("I let people laugh at me or make fun at my expense") and its context part ("I let people offend me or look down one me more than I should"). The former reduced the humour behaviour to its core and the latter leaves the item intact and only eliminates the reference to humour. It appears that for self-defeating humour the resulting core should be close to what is commonly known as "laughing at yourself" (or self-deprecating humour), but an evaluation that one practiced laughing at oneself too much or that negative feelings remain renders this core to what the self-defeating humour style measures.

In Study 2, these two scales (Humour- and Context-HSQ) will be employed to test the incremental validity of the HSQ over and above context in predicting psychological wellbeing, and the relation of the humour content in the HSQ with personality, well-being and other humour instruments.

\section{Study 2}

Study 2 entails both a replication and a method study. More precisely, it aimed at (a) providing an independent examination of the incremental validity of the HSQ over and above personality in predicting psychological well-being, (b) determining if the relations of the HSQ humour styles with psychological well-being are driven by their context components and (c) investigating the relations of the HSQ humour version (especially the two "negative" humour styles) with personality, psychological well-being and other humour measures (coping 


\section{European Journal of Humour Research1(4)}

humour, verbal humour, laughing at yourself, humour under stress and playfulness). Specifically, it is expected that the humour component of the self-defeating humour style will correlate highly with "laughing at yourself", but not with "maladaptive" personality traits (like neuroticism) or lower psychological well-being. The humour component of the aggressive humour style should correlate highly with other humour instruments due to its cheerful and humour-producing components. Playfulness was expected to go along with all humour components of the HSQ, as a playful frame of mind was described as a precondition for humour (e.g., McGhee, 1999)

\subsection{Materials and methods}

\subsubsection{Participants}

A total of 164 participants (18 per cent men) with a median age of $24(M=28.45, S D=$ 10.25) ranging from 17 to 62 years provided valid responses in this study. Most participants were Swiss (60 per cent), German (33 per cent) and from several other nations. Overall, they were well-educated, with 35 per cent being college or university students, 34 per cent having passed tertiary education, 24 per cent having A-levels and six per cent having an apprenticeship.

\subsubsection{Instruments}

$H S Q$. Cronbach's alpha in Study 2 ranged from .69 (aggressive) to .92 (affiliative).

Humour version derived from the HSQ (Humour-HSQ; Ruch \& Heintz, 2014). This questionnaire assesses the HSQ humour styles reduced to their core contents without any or only minimal contextual information. Sample items are "I laugh and joke a lot" (affiliative), "I can usually cheer myself up with humour" (self-enhancing), "I often tease others" (aggressive), and "I often make jokes about myself or make fun of myself" (self-defeating). The instrument employs a seven-point Likert scale from "totally disagree" (1) to "totally agree" (7). Cronbach's alpha ranged from .79 (aggressive) to .94 (affiliative).

Context version derived from the HSQ (Context-HSQ; Ruch \& Heintz, 2014). This instrument assesses individual differences in the extra-humorous elements that are inherent in the HSQ items. Sample items are "I enjoy impressing people" (affiliative), "If I am feeling upset or unhappy I usually try to think of something beautiful about the situation to make myself feel better" (self-enhancing), "If I don't like someone, I often criticize or reproach them to put them down" (aggressive), and "I let people offend me or look down one me more than I should" (self-defeating). The instrument employs a seven-point Likert scale from "totally disagree" (1) to "totally agree" (7). The context does not need to be homogeneous but ideally varies to average out unwanted variance. Nevertheless, Cronbach's alpha was computed and ranged from .70 to .83 (affiliative), except for the aggressive context scale (.39).

The same personality and well-being instruments as in Study 1 were administered, and all yielded sufficient reliabilities. Cronbach's alpha ranged from .68 to .90 in the BFI, and it was .89 for the SWLS, .87 for positive affect, .84 for negative affect (the PANAS), .92 for the RSES, .85 for the LOT-R and .93 for the CES-D Scale.

Coping Humor Scale (CHS; Martin \& Lefcourt, 1983). The seven-item CHS measures the use of humour to cope with stress (e.g., "I usually look for something comical to say when I am in tense situations"). The scale employs a four-point Likert scale from "strongly disagree" (1) to "strongly agree" (4). Cronbach's alpha was .61 (in the current study .71). 


\section{European Journal of Humour Research1(4)}

Modified version of the Sense of Humor Scale (SHS; McGhee, 1999). The 40-item SHS employs a seven-point Likert scale from "strongly disagree" (1) to "strongly agree" (7) and originally has eight scales (playful vs. serious attitude, positive vs. negative mood and six sense of humour facets with four items each). For the current study, three of these facets were selected and adapted to enhance reliability, namely verbal humour (e.g., "I often tell funny stories"), laughing at yourself (e.g., "I find it easy to laugh when I am the butt of the joke") and humour under stress (e.g., "My sense of humor is my most effective tool in coping with life stress"). Three of the original items of each scale were supplemented by two newly generated items based on the facet definitions (McGhee, 1999). Internal consistencies (Cronbach's alpha) for the German version of the original four-item scales ranged from .53 to .88 (Proyer, Ruch \& Müller, 2010). In an unpublished pilot study (Ruch, Heintz \& Auerbach, 2012), the newly created scales (with five items each) correlated $r>.91$ with McGhee's original scales, and Cronbach's alpha ranged from .83 to .87 (in the current study .78 to .83 ).

Short Measure of Playfulness (SMAP; Proyer, 2012). The five-item SMAP measures adult playfulness (e.g., "I am a playful person"). The scale employs a four-point Likert scale from "strongly disagree" (1) to "strongly agree" (4). Cronbach's alpha was .80 to .89 (in the current study .90).

\subsubsection{Procedure}

The data were collected in an online survey using recruitment venues similar to Study 1 . To create the Humour-HSQ, the $32 \mathrm{HSQ}$ items were rephrased to only capture the relevant humour components, resulting in four humour scales. For the Context-HSQ, the humourrelated words in the $32 \mathrm{HSQ}$ items were replaced by non-humorous counterparts. Both objective (dictionaries) and subjective (expert ratings) methods were employed to ensure that the context scales were indeed devoid of any humor. The items of the two newly constructed scales are listed in the appendix. Details regarding the development and descriptive properties of the Humour-HSQ and the Context-HSQ are described elsewhere (Ruch \& Heintz, 2014).

\subsubsection{Analyses}

Pearson correlations were used to determine the relations among the HSQ, the Humour-HSQ and the Context-HSQ with personality, psychological well-being and humour. Hierarchical multiple regression analyses were conducted to determine the amount of incremental validity of the HSQ over and above personality in predicting psychological well-being. Hierarchical regression analyses were also conducted to determine the amount of incremental validity of the HSQ over and above context in predicting psychological well-being. 


\section{European Journal of Humour Researchl(4)}

Table 3. Means and standard deviations of the personality, well-being and humour measures and their correlations with the Humor Styles Questionnaire (HSQ) and the derived context and humour versions.

\begin{tabular}{|c|c|c|c|c|c|c|c|c|c|c|c|c|c|c|}
\hline & \multirow[b]{2}{*}{$M$} & \multirow[b]{2}{*}{$S D$} & \multicolumn{4}{|c|}{$\underline{\mathrm{HSQ}}$} & \multicolumn{4}{|c|}{ Context-HSQ } & \multicolumn{4}{|c|}{ Humour-HSQ } \\
\hline & & & $\mathrm{AF}$ & SE & $\mathrm{AG}$ & SD & $\mathrm{AF}$ & $\mathrm{SE}$ & $\mathrm{AG}$ & SD & $\mathrm{AF}$ & $\mathrm{SE}$ & $\mathrm{AG}$ & SD \\
\hline \multicolumn{15}{|l|}{ BFI } \\
\hline $\mathrm{E}$ & 3.28 & 0.88 & $.64 *$ & $.43^{*}$ & .07 & -.23 & $.81 *$ & $.31 *$ & .21 & $-.35 *$ & $.62 *$ & $.52 *$ & .19 & $.29 *$ \\
\hline A & 3.68 & 0.55 & .13 & $.44 *$ & $-.50 *$ & $-.31 *$ & .23 & $.44 *$ & $-.44 *$ & $-.30 *$ & .08 & $.32 *$ & $-.29 *$ & -.01 \\
\hline $\mathrm{C}$ & 3.44 & 0.73 & .01 & .19 & -.13 & -.25 & .22 & $.34 *$ & -.16 & $-.32 *$ & .02 & .12 & -.15 & -.10 \\
\hline $\mathrm{N}$ & 3.14 & 0.79 & -.16 & $-.47 *$ & .10 & $.35^{*}$ & $-.33^{*}$ & $-.53 *$ & .12 & $.45^{*}$ & -.15 & $-.43 *$ & .00 & .04 \\
\hline $\mathrm{O}$ & 3.83 & 0.64 & $.33 *$ & $.40^{*}$ & -.20 & -.24 & $.33 *$ & $.37 *$ & -.10 & -.21 & $.35^{*}$ & $.43^{*}$ & -.07 & .04 \\
\hline \multicolumn{15}{|l|}{ Well-being } \\
\hline SWLS & 4.46 & 1.33 & .20 & $.31 *$ & .06 & -.22 & $.36^{*}$ & $.43^{*}$ & -.03 & -.21 & .19 & $.32 *$ & .12 & .11 \\
\hline PA & 32.73 & 6.73 & $.27 *$ & $.48^{*}$ & -.04 & $-.27 *$ & $.53^{*}$ & $.53 *$ & .04 & $-.31 *$ & $.27 *$ & $.48 *$ & .03 & .09 \\
\hline NA & 20.43 & 6.36 & -.19 & $-.28 *$ & -.05 & $.26^{*}$ & -.25 & $-.27 *$ & -.03 & $.43^{*}$ & -.20 & $-.26 *$ & -.12 & -.01 \\
\hline Self-esteem & 30.46 & 6.53 & .25 & $.45^{*}$ & -.15 & $-.41 *$ & $.48^{*}$ & $.49 *$ & -.09 & $-.45 *$ & $.26 *$ & $.43^{*}$ & -.08 & -.02 \\
\hline Optimism & 20.96 & 4.76 & $.27 *$ & $.45^{*}$ & -.07 & $-.45 *$ & $.50 *$ & $.54 *$ & .01 & $-.42 *$ & .22 & $.45^{*}$ & .00 & -.03 \\
\hline Depression & 35.78 & 11.32 & -.22 & $-.44 *$ & .02 & $.32 *$ & $-.37 *$ & $-.50 *$ & .01 & $.32 *$ & -.20 & $-.38 *$ & -.07 & .00 \\
\hline \multicolumn{15}{|l|}{ Humour } \\
\hline CHS & 18.30 & 3.25 & $.46^{*}$ & $.69 *$ & .00 & -.05 & $.36^{*}$ & $.43^{*}$ & .03 & -.19 & $.46^{*}$ & $.70^{*}$ & .16 & .24 \\
\hline SHS verbal & 4.58 & 1.27 & $.78 *$ & $.30 *$ & .25 & .08 & $.50 *$ & .04 & $.27 *$ & .00 & $.79 *$ & $.54 *$ & $.52 *$ & $.51 *$ \\
\hline SHS LAY & 4.94 & 1.06 & $.55^{*}$ & $.42 *$ & .17 & .22 & $.42 *$ & $.28 *$ & .08 & -.07 & $.53 *$ & $.58 *$ & $.41 *$ & $.74 *$ \\
\hline SHS stress & 4.43 & 1.14 & $.56^{*}$ & $.59 *$ & .04 & -.02 & $.43^{*}$ & .24 & .09 & -.13 & $.59 *$ & $.72 *$ & $.30 *$ & $.41 *$ \\
\hline SMAP & 2.76 & 0.70 & $.52 *$ & $.40 *$ & .08 & .06 & $36^{*}$ & .21 & .12 & .04 & $.53 *$ & $.52 *$ & $.28 *$ & $.38 *$ \\
\hline
\end{tabular}

Note. $N=164 . \mathrm{AF}=$ affiliative, $\mathrm{SE}=$ self-enhancing, $\mathrm{AG}=$ aggressive, $\mathrm{SD}=$ self-defeating $\mathrm{BFI}=\mathrm{Big}$ Five Inventory, $\mathrm{E}=$ extraversion, $\mathrm{A}=$ agreeablenes

$\mathrm{C}=$ conscientiousness, $\mathrm{N}=$ neuroticism, $\mathrm{O}=$ openness, $\mathrm{SWLS}=$ Satisfaction With Life Scale, PA = positive affect, NA = negative affect, CHS = Coping Humor Scale, SHS = modified version of the Sense of Humor Scale, LAY = laughing at yourself, SMAP = Short Measure of Adult Playfulness.

$* p<.001$ (adjusted level of significance due to alpha error accumulation). 


\subsection{Results}

\subsubsection{Correlations between the variants of the HSQ and personality, well-being and humour}

Table 3 presents the means and standard deviations of the personality, well-being and humour measures and their correlations with the HSQ and the derived context and humour versions.

Table 3 shows that the patterns of correlations of personality with the HSQ, the Context-HSQ and the Humour-HSQ were relatively comparable for the affiliative, selfenhancing and aggressive scales; there were some differences in the magnitude of the coefficients and occasionally coefficients differed in being significant or not. The selfdefeating scale had an unfavourable personality profile (low in agreeableness, conscientiousness and extraversion and high in neuroticism) with small to medium negative coefficients in the HSQ and the Context-HSQ, but a positive one (high extraversion) in the Humour-HSQ.

Regarding the well-being measures, correlations were highest for the Context-HSQ (with medium to large effects), while they were small to medium for the HSQ and the Humour-HSQ. Correlation patterns of the self-enhancing and aggressive scales were similar across all the HSQ-versions: Self-enhancing correlated medium to high with better psychological well-being (across all six measures), while aggressive was uncorrelated with all of them. Finally, the HSQ and the Context-HSQ self-defeating scales went along with lower well-being (medium to large effects except for life satisfaction), while the Humour-HSQ was unrelated to all well-being measures.

The correlations of all affiliative scales with the examined humour measures were positive and significant (with large effects), albeit, as expected, somewhat lower in magnitude for the Context-HSQ. For the self-enhancing scale, the HSQ and Humour-HSQ showed similar patterns of positive correlations, with the Humour-HSQ having numerically higher coefficients. In contrast, the context only exhibited low to medium correlations (most strongly so with the CHS). The verbal humour subscale of the SHS was the only scale completely unrelated to the Context-HSQ self-enhancing scale. Both the aggressive and self-defeating scales of the HSQ and the Context-HSQ were mostly uncorrelated with the five humour measures (the exception being a low positive correlation of the aggressive scale and the verbal humour subscale of the SHS). In sharp contrast, the respective scales of the Humour-HSQ correlated positively medium to high with the humour measures (with the exception of the CHS). Aggressive humour was most strongly related to the verbal humour subscale of the SHS, while self-defeating was, as predicted, most strongly related to the laughing at yourself subscale.

\subsubsection{Incremental validity of the HSQ beyond personality}

Table 4 shows the hierarchical multiple regression analyses predicting the six measures of psychological well-being with personality in step 1 (enter method) and with the four scales of the HSQ in step 2 (stepwise method).

As can be seen in Table 4, personality explained between 26 per cent (life satisfaction) and 61 per cent (negative affect) of the variance in the psychological well-being measures. The four humour styles showed no incremental validity for two measures (life satisfaction and negative affect) and a significant incremental validity of two to six per cent in positive affect, self-esteem, optimism and depression. Regarding the beta weights, the self-defeating humour 
European Journal of Humour Research1 $(3 \& 4)$

Table 4. Hierarchical multiple regression analyses predicting various measures of psychological well-being with the Big Five Inventory (BFI) personality traits in step 1 (enter method) and with the four scales of the Humor Styles Questionnaire (HSQ) in step 2 (stepwise method, final solution reported).

\begin{tabular}{|c|c|c|c|c|c|c|c|c|c|c|c|c|}
\hline \multirow[b]{2}{*}{ Predictor } & \multicolumn{2}{|c|}{$\underline{\text { Life satisfaction }}$} & \multicolumn{2}{|c|}{$\underline{\text { Positive affect }}$} & \multicolumn{2}{|c|}{$\underline{\text { Negative affect }}$} & \multicolumn{2}{|c|}{$\underline{\text { Self-esteem }}$} & \multicolumn{2}{|c|}{$\underline{\text { Optimism }}$} & \multicolumn{2}{|c|}{$\underline{\text { Depression }}$} \\
\hline & $\Delta R^{2}$ & $\beta$ & $\Delta R^{2}$ & B & $\Delta R^{2}$ & $\beta$ & $\Delta R^{2}$ & $\beta$ & $\Delta R^{2}$ & $\beta$ & $\Delta R^{2}$ & $\beta$ \\
\hline Step 1 & $.26 * * *$ & & $.57 * * *$ & & $.61 * * *$ & & $.51 * * *$ & & $.45 * * *$ & & $.40 * * *$ & \\
\hline BFI E & & $.27 * * *$ & & $.34 * * *$ & & -.11 & & $.26 * * *$ & & $.27 * * *$ & & $-.21 * *$ \\
\hline BFI A & & -.02 & & -.10 & & -.03 & & -.07 & & .02 & & .11 \\
\hline BFI C & & .14 & & $.29 * * *$ & & -.08 & & $.22 * * *$ & & .10 & & $-.17 * *$ \\
\hline BFI N & & $-.29 * * *$ & & $-.26 * * *$ & & $.54 * * *$ & & $-.43 * * *$ & & $-.43 * * *$ & & $.44 * * *$ \\
\hline BFI O & & -.01 & & $.27 * * *$ & & $.17 *$ & & $.14^{*}$ & & .08 & & $-.14^{*}$ \\
\hline Step 2 & - & & $.02 *$ & & - & & $.03 * *$ & & $.06 * * *$ & & $.02 *$ & \\
\hline HSQ AF & & - & & $-.14 *$ & & - & & - & & - & & - \\
\hline HSQ SE & & - & & $.16^{*}$ & & - & & $.15^{*}$ & & $.17 *$ & & $-.17 *$ \\
\hline HSQ AG & & - & & - & & - & & & & - & & - \\
\hline HSQ SD & & - & & - & & - & & $-.19 * *$ & & $-.27 * * *$ & & - \\
\hline Total $R^{2}$ & $.26 * * *$ & & $.59 * * *$ & & $.61 * * *$ & & $.54 * * *$ & & $.51 * * *$ & & $.42 * * *$ & \\
\hline
\end{tabular}

Note. $N=164$. $\mathrm{E}=$ extraversion, $\mathrm{A}=$ agreeableness, $\mathrm{C}=$ conscientiousness, $\mathrm{N}=$ neuroticism, $\mathrm{O}=$ openness, $\mathrm{AF}=$ affiliative, $\mathrm{SE}=$ self-enhancing, $\mathrm{AG}=$ aggressive, $\mathrm{SD}=$ self-defeating.

$* p<.05 . * * p<.01 . * * * p<.001$. 


\section{European Journal of Humour Research1(3\&4)}

Table 5. Hierarchical multiple regression analyses (enter method) predicting psychological well-being with the context version of the Humor Styles Questionnaire (HSQ) in step 1 and the HSQ in step 2(separately for each humour style).

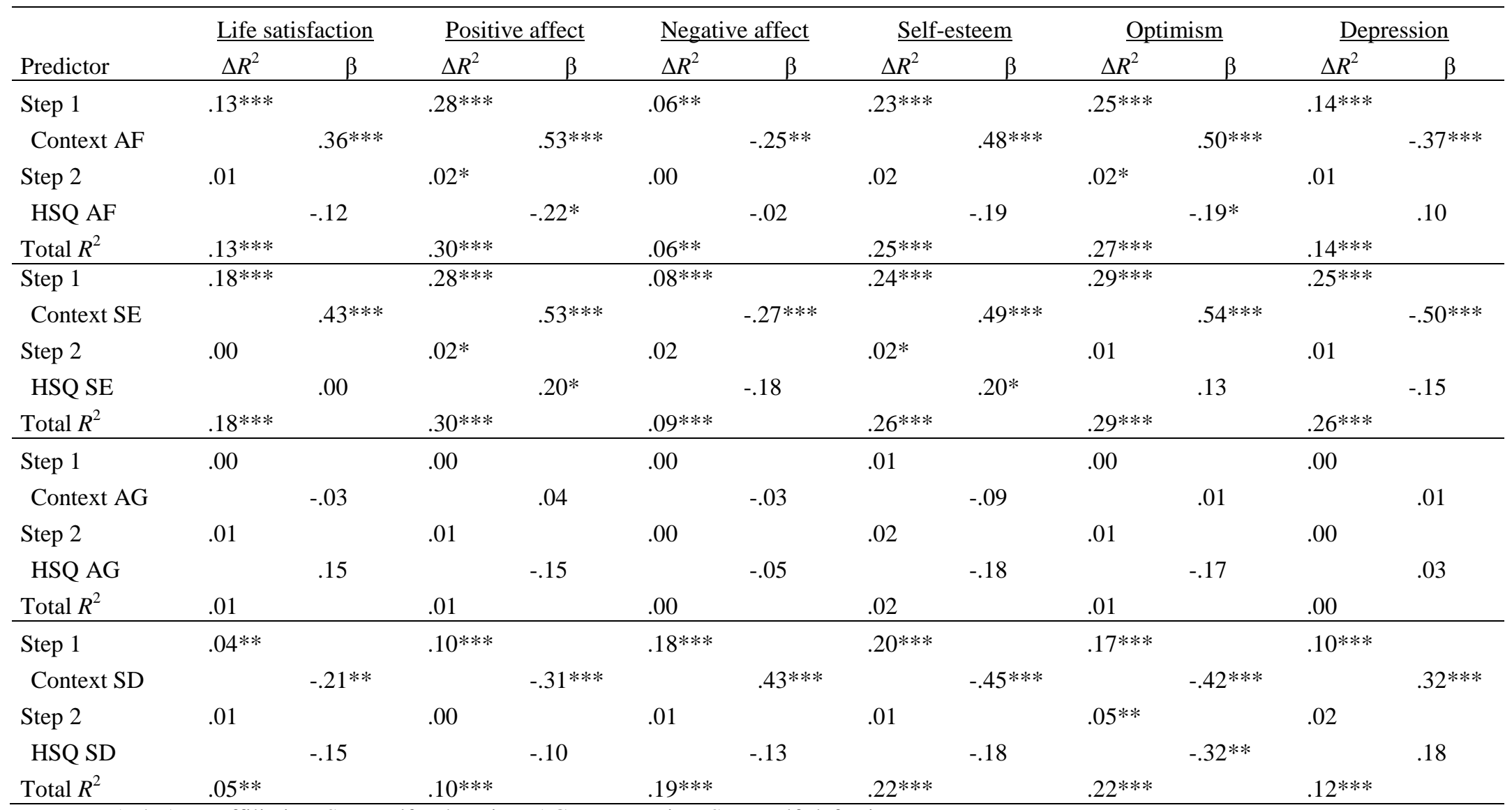

Note. $N=164 . \mathrm{AF}=$ affiliative, $\mathrm{SE}=$ self-enhancing, $\mathrm{AG}=$ aggressive, $\mathrm{SD}=$ self-defeating.

$* p<.05 . * * p<.01 . * * * p<.001$. 
style remained a significant negative predictor of self-esteem and optimism. The selfenhancing humour style was a significant positive predictor over and above personality for positive affect, self-esteem and optimism and a negative predictor for depression. In addition, the affiliative humour style emerged as a significant negative predictor of positive affect. Note that the inverse analysis (incremental validity of the FFM beyond the four humour styles) yielded medium to large effect sizes $\left(.10<\Delta R^{2}<.29\right)$.

\subsubsection{The role of context in predicting psychological well-being}

Table 5 shows the hierarchical multiple regression analyses (enter method) predicting the six measures of psychological well-being with the Context-HSQ (step 1) and the HSQ (step 2), separately for each humour style.

As can be seen in Table 5, the HSQ humour styles explained between zero to five per cent of variance in the well-being measures over and above context. The HSQ affiliative style predicted two per cent of the variance in positive affect and optimism beyond the affiliative context, yet the beta weights were negative. The HSQ self-enhancing humour style positively predicted positive affect $\left(\Delta R^{2}=\right.$ two per cent $)$ and self-esteem $\left(\Delta R^{2}=\right.$ two per cent $)$ over and above the self-enhancing context. Lastly, the HSQ self-defeating humour style negatively predicted optimism ( $\Delta R^{2}=$ five per cent) beyond the self-defeating context scale. Thus, the four humour styles exhibited significant incremental validity in predicting psychological wellbeing in 5 of 24 analyses (18 if the aggressive style is excluded) and had small effects.

\subsection{Discussion}

Overall, Study 2 had three aims: (a) to replicate the main findings of Study 1, (b) to determine if the relations of the HSQ humour styles with personality and psychological well-being are driven by their context components and (c) to investigate the relations of the HSQ humour version (especially the two "negative" humour styles) to personality, well-being and other humour measures. Regarding aim (a), the low incremental validity of the HSQ over and above personality in predicting psychological well-being was confirmed. In contrast to Study 1, the self-enhancing humour style emerged as a more potent predictor than the self-defeating humour style (comparable to the findings of Jovanovic, 2011). These results are also in line with two articles published since the planning of the current studies. Dyck and Holtzman (2013) examined the relation of the four humour styles with depression and life satisfaction, controlling for neuroticism, physical symptoms and gender. The relations were small and significant for the affiliative, self-enhancing and self-defeating humour styles $(\beta \mathrm{s}<|.18|, p \mathrm{~s}<$ $.05)$ when these variables were controlled for. Páez et al. (2013) investigated the incremental validity of humour styles in predicting happiness and psychological well-being. After controlling for the FFM personality traits and an alexithymia score, the self-enhancing ( $\beta=$ $.24, p<.01)$ and self-defeating $(\beta=-.25, p<.01)$ humour styles remained small and significant predictors of happiness and psychological well-being, respectively.

Regarding aim (b), most of the relations of the HSQ humour styles with well-being were attributable to context. The medium to large zero-order correlations were reduced to non-significance or yielded small effects once context was controlled for (most strongly so for the self-enhancing and self-defeating humour styles). Thus, it was not humour, but the context descriptions that drove the strong relations of the HSQ with psychological well-being.

Regarding aim (c), the hypothesis was confirmed that the humour component of the self-defeating humour style would correlate highly with the laughing at yourself subscale by McGhee (1999). The finding that self-defeating humour did not correlate with neuroticism, lower agreeableness and lower well-being is also in line with the conception of laughing at 
yourself. A similar finding was observed for aggressive humour: While the aggressive humour style was unrelated to other humour measures, the aggressive humour component related strongly to them. Thus, the humour components of these two humour styles were neither detrimental to well-being nor generally maladaptive, but were similar to other measures of humour production and playfulness. It is noteworthy that both the Context- and the Humour-HSQ version yielded converging results, i.e., the self-defeating humour content was not maladaptive in its correlations with personality and psychological well-being, and the negative impact of the respective HSQ scale vanished when context was controlled for (except for optimism, where it still had a medium effect size).

However, several limitations of the method study part need to be mentioned. First, as mentioned before, we cannot distinguish absolutely sharply between humour content and context. Hence, to estimate the degree of subjectivity of the separation, interrater agreement needs to be studied (see Ruch \& Heintz, 2014). In addition, more test forms could be developed and examined in studies. A second limitation is that we only tested one (of several possible) context versions and thus our findings cannot be generalized. This needs to be empirically tested; however, we would not expect that replacing the humour content by a different word would lead to essentially different results. Another limitation is that we lumped all the context factors together rather than studying them individually. As we mentioned, the context comprised a variety of descriptions, like social situations, feelings, moods and intentions. Testing them in isolation will help to find out which ones enhance or lower the validity of the scale. We hereby argue that some of these contextual factors are essential, yet they should vary to balance out and to make the variance due to the content stronger. The idea of functions of humour poses a dilemma in this respect. Functions allow speculating about consequences of humour behaviour, and this requires a decision of whether or not one should include the consequences of humour already in the items. If one does so, special care needs to be taken to demonstrate that the prediction of a criterion does not depend solely on this variance and to examine whether or not it modifies the variance generated by the humour content.

All in all, it is evident that we do not advocate that items of a humour scale (or any other questionnaire) should be without any context, yet the kind of context, its homogeneity and its relation to the content intended to be assessed need to be taken into account.

\section{Overall discussion}

Taken together, the two studies revealed a low incremental validity of the HSQ in predicting psychological well-being over and above personality and (humour-removed) context Specifically, the FFM personality traits and the context of the HSQ scales were the strongest predictors for six well-being measures (life satisfaction, positive and negative affect, selfesteem, optimism and depression). The HSQ humour styles became either non-significant or were contributing small effects over and above personality and context. Thus, the strength of the HSQ in predicting psychological well-being is obviously to a large extent a method effect introduced by the strong context wording of the HSQ items. When this context is controlled for, the "pure" humour entailed in the HSQ shows effects similar to those of other humour measures (i.e., inconsistent relations and small effect sizes).

However, the relatively low incremental validity of the HSQ over and above personality and context should not be seen too pessimistic. First, the zero-order correlations with psychological well-being were substantial and in the expected directions. Eliminating the context lowered the prediction to small and medium effects, which, however, is more in accordance with the size of the effects humour and laughter have on psychological well-being 
in experiments and interventions studies. In other words, if we can replicate small correlations that are indeed due to humour (and nothing else), then this lends firm support for the role humour plays in psychological health. Overly large effect sizes in questionnaire studies may be criticized to be inflated by a method overlap or, as Study 2 suggests more specifically, by overlapping contexts.

These findings are also in line with the results reported by Ruch and Heintz (2014), in that the self-defeating humour style was mostly determined by context (rather than humour per se) and that the differentiation among the four humour styles was mostly driven by (dissimilar) contexts, while the humour components of the four HSQ scales were rather similar (scale intercorrelations between .33<r<.65, ps $<.001$ ). Study 1 and 2 also strengthen and extend the Páez et al. (2013) findings that the self-enhancing and selfdefeating humour styles remain in some cases small but significant predictors of psychological well-being beyond personality.

The correlation patterns with other humour instruments challenge the novelty and the unfavourableness of the humour components of the aggressive and self-defeating humour styles. Each scale of the Humour-HSQ correlated positively with the five humour measures employed (i.e., coping humour, verbal humour, laughing at yourself, humour under stress and playfulness). Thus, aggressive humour is rather conceptualized as producing verbal humour (like teasing others or "sharp wit") and self-defeating humour as laughing at yourself (like making jokes about oneself). The results for aggressive humour seem surprising, but the "humour vocabulary" in these items relates to "using humour", "teasing" and to maximally "laughing at". Thus, not surprisingly the use of these humour contents does not appear too negative and correlates positively with other humour scales. Clearly, the aggressive flavour is build into the item context (often intentions like offending or criticising others and acting impulsively).

In general, one needs to decide if "humour style" refers only to the style, form or flavour of humour involved. Only this style can be "used" (in the sense of shown frequently) and this can be interpreted as the (humour-related) cause of an outcome. If "humour style" relates the combined package (i.e., humour plus context), then it is difficult to see how this style can be "used" (including its non-humour context variables) and it cannot be interpreted as a (humour-related) cause of an outcome. It cannot be "used", as one would not only need to laugh at oneself, but also to feel bad about it. For example, depression cannot be seen as a consequence of laughing at oneself frequently, but it might be a cause for feeling bad despite engaging in humour; i.e., it might lead to a mix of amusement and negative emotions. The participants decide whether they laugh at themselves "too much". The overuse is not due to a high frequency, but due to the combination with a negative evaluation. Clearly this element is not inherent in the humour behaviour, but comes from other conditions. We are therefore inclined to say that this is not part of a flavour, style or type of humour, but added to it. It should be emphasized that it is perfectly all right to combine these elements in a scale of humour and to use this scale in research. It is only problematic to make the negative evaluation of the humour by the participant part of a "style" of humour (as it is not a genuine part of the humour), and to interpret correlations or other results in a way that the negative evaluation is either part of humour or a humour-related cause.

\subsection{Limitations}

One limitation of the current studies is their cross-sectional measurement. Although personality and well-being are "predicted", this does not infer any causality. To establish causality from humour to well-being, longitudinal and/or experimental designs are needed. 
Secondly, the two studies only involved self-reports. Employing other modes of data collection, such as peer-ratings and observations, would enrich the conclusions that could be drawn by supporting the construct validity of the measures. Thirdly, mainly well-educated females took part in the studies. Thus the conclusions might not be generalizable across the general population, and replications of the findings with divergent samples are desirable. Fourth, as the results showed that context is important, we have to acknowledge that this study is limited to one culture only. Culture is a strong context factor and replications in different cultures are needed. Finally, and most importantly, the present study is of a psychometric nature. Questionnaire variances have been decomposed and causes of these variances have been identified. Experimental research is needed to actually induce these humour behaviours and to see if there is actually a change in well-being.

\subsection{Implications for further research}

Despite these limitations, the current studies add to the growing literature on humour styles in very important ways. Firstly, they hint to the need for further studies on the validity of the humour styles, especially using peer-reports and observations of actual humour behaviours or the usage of humour in everyday life. An instrument can be recommended for usage if its validity (mainly construct validity, but also content and incremental validity) is established and sufficient. The current studies showed that the incremental validity of the HSQ in predicting psychological well-being beyond established measures was insufficient, and that the interpretability of the humour components in the HSQ is questionable. The nature of the humour core of the humour styles could be a research question for further studies. For example, what typical humour-related actions, thoughts and feelings make up the core and how do those differ across the four styles? Regarding the routine use of the HSQ, the question arises whether or not the authors want to reduce the context from the items somewhat (thereby making them more content-saturated) without changing their intended meaning. A reduction to the scale used in the present study might however not be desirable.

\subsection{Conclusions}

To summarise, the current studies analysed the incremental validity of and the role of humour in the HSQ. The four humour styles had a low incremental validity in predicting six measures of psychological well-being beyond personality and (non-humour related) context. Contextrather than humour per se-was also the reason why the HSQ correlated highly with psychological well-being. The humour components of the four humour styles overlapped with other humour instruments and none of them was detrimental to well-being or maladaptive.

Ultimately, a valid and comprehensive taxonomy of humour is necessary to advance the field of humour research, and to finally clarify the role of humour in everyday life, personality and well-being. The HSQ tried to fulfil this goal for everyday functions of humour, yet the current findings cast doubts on its accomplishments. Also, this classification does not claim to comprehensive for the entire field of humour. It seems that humour research should spend more time on basic research on the concepts before questionnaires are developed. 


\section{Appendix}

Overview of the 32 items of the Context- and the Humour-HSQ

\begin{tabular}{|c|c|c|c|}
\hline Scale & Item & Context-HSQ & Humour-HSQ \\
\hline $\mathrm{AF}$ & 1 & $\begin{array}{l}\text { I usually don't talk or converse much with } \\
\text { other people. [inverse] }\end{array}$ & $\begin{array}{l}\text { I usually don't laugh or joke } \\
\text { around much. [inverse] }\end{array}$ \\
\hline SE & 2 & $\begin{array}{l}\text { If I am feeling depressed, I can usually put } \\
\text { myself in a better mood with something } \\
\text { beautiful. }\end{array}$ & $\begin{array}{l}\text { I can usually cheer myself up } \\
\text { with humor. }\end{array}$ \\
\hline $\mathrm{AG}$ & 3 & $\begin{array}{l}\text { If someone makes a mistake, I will often } \\
\text { reproach them about it. }\end{array}$ & I often tease others. \\
\hline SD & 4 & $\begin{array}{l}\text { I let people offend me or look down one me } \\
\text { more than I should. }\end{array}$ & $\begin{array}{l}\text { I let people laugh at me or } \\
\text { make fun at my expense. }\end{array}$ \\
\hline $\mathrm{AF}$ & 5 & $\begin{array}{l}\text { I don't have to work very hard at impressing } \\
\text { other people -- I seem to be a naturally } \\
\text { influencing person. }\end{array}$ & $\begin{array}{l}\text { I make others laugh easily -- I } \\
\text { am a humorous person. }\end{array}$ \\
\hline SE & 6 & $\begin{array}{l}\text { Even when I'm by myself, I often occupy } \\
\text { myself with the little things in life. }\end{array}$ & $\begin{array}{l}\text { I'm often amused by the } \\
\text { absurdities of life. }\end{array}$ \\
\hline $\mathrm{AG}$ & 7 & $\begin{array}{l}\text { People are never offended or hurt by my } \\
\text { manner of speaking. [inverse] }\end{array}$ & $\begin{array}{l}\text { My sense of humor is never } \\
\text { offending or hurting. [inverse] }\end{array}$ \\
\hline SD & 8 & $\begin{array}{l}\text { I will often get carried away in putting } \\
\text { myself down if it makes my family or friends } \\
\text { feel good. }\end{array}$ & $\begin{array}{l}\text { I often put myself down and } \\
\text { thus make others laugh. }\end{array}$ \\
\hline $\mathrm{AF}$ & 9 & $\begin{array}{l}\text { I rarely impress other people by telling } \\
\text { enthralling stories about myself. [inverse] }\end{array}$ & $\begin{array}{l}\text { I rarely tell funny stories } \\
\text { about myself, which make } \\
\text { others laugh. [inverse] }\end{array}$ \\
\hline SE & 10 & $\begin{array}{l}\text { If I am feeling upset or unhappy, I usually try } \\
\text { to think of something beautiful about the } \\
\text { situation to make myself feel better. }\end{array}$ & $\begin{array}{l}\text { I usually try to think of } \\
\text { something funny about a } \\
\text { situation. }\end{array}$ \\
\hline $\mathrm{AG}$ & 11 & $\begin{array}{l}\text { When telling experiences or saying } \\
\text { enthralling things, I am usually not very } \\
\text { concerned about how other people are taking } \\
\text { it. }\end{array}$ & $\begin{array}{l}\text { I usually tell jokes or say } \\
\text { funny things. }\end{array}$ \\
\hline SD & 12 & $\begin{array}{l}\text { I often try to make people like or accept me } \\
\text { more by saying something appealing about } \\
\text { my own weaknesses, misapprehensions, or } \\
\text { faults. }\end{array}$ & $\begin{array}{l}\text { I often say something funny } \\
\text { about my own weaknesses, } \\
\text { blunders, or faults. }\end{array}$ \\
\hline $\mathrm{AF}$ & 13 & I talk or converse a lot with my friends. & I laugh and joke a lot. \\
\hline SE & 14 & $\begin{array}{l}\text { My positive outlook on life keeps me from } \\
\text { getting overly upset or depressed about } \\
\text { things. }\end{array}$ & $\begin{array}{l}\text { I have a humorous outlook on } \\
\text { life. }\end{array}$ \\
\hline $\mathrm{AG}$ & 15 & $\begin{array}{l}\text { I do not like it when people tell experiences } \\
\text { or say things as a way of criticizing or } \\
\text { putting someone down. [inverse] }\end{array}$ & $\begin{array}{l}\text { I do not like criticizing or } \\
\text { putting-down humor. [inverse] }\end{array}$ \\
\hline SD & 16 & $\begin{array}{l}\text { I don't often say enthralling things to put } \\
\text { myself down. [inverse] }\end{array}$ & $\begin{array}{l}\text { I rarely say funny things about } \\
\text { myself. [inverse] }\end{array}$ \\
\hline $\mathrm{AF}$ & 17 & $\begin{array}{l}\text { I usually don't like to tell experiences or to } \\
\text { impress people. [inverse] }\end{array}$ & $\begin{array}{l}\text { I usually don't tell jokes or } \\
\text { amuse people. [inverse] }\end{array}$ \\
\hline
\end{tabular}


SE

If I'm by myself and I'm feeling unhappy, I make an effort to think of something beautiful to make me feel better.

AG 19 Sometimes I think of something that is so enthralling that I can't stop myself from saying it, even if it is not appropriate for the situation.

SD $20 \quad$ I often go overboard in putting myself down when I am telling experiences or trying to be communicative.

AF $21 \quad$ I enjoy impressing people.

SE 22 If I am feeling sad or upset, I usually lose my serenity. [inverse]

AG 23 I never participate in offending others even if all my friends are doing it. [inverse]

SD 24 When I am with friends or family, I often seem to be the one that other people look down on or offend.

AF $25 \quad$ I don't often converse with my friends. [inverse]

SE $26 \quad$ It is my experience that thinking about some beautiful aspect of a situation is often a very effective way of coping with problems.

AG 27 If I don't like someone, I often criticize or reproach them to put them down.

SD $\quad 28$

28 I often cover it up by telling an experience so that even my closest friends don't know how I really feel.

AF 29 I usually can't think of enthralling things to say when I'm with other people. [inverse]

SE $\quad 30 \quad$ I don't need to be with other people to feel good -- I can usually find things to occupy myself with even when I'm by myself.

AG 31 Even if something is really relevant to me, I will not say anything or criticize it if someone will be offended. [inverse]

SD $\quad 32$ Letting others offend me is my way of making my friends and family feel good.
I always think of something

funny to cheer myself up.

Sometimes I think of extremely funny things.

I often make jokes about myself or make fun of myself.

I make people laugh.

I never lose my sense of humor.

I never laugh at others.

[inverse]

I let others often make fun of me or joke about me.

I don't often joke around. [inverse]

I often think about some amusing aspect of a situation.

I often use humor about others or tease them.

I often joke around.

I usually can't think of witty things. [inverse]

I am usually amused and I can find things to laugh about.

I always laugh or joke about something that is really funny to me.

I let others laugh at me, which keeps them in in good spirits.

Note. The order of the items is the same as in the HSQ (Martin et al., 2003); AF = affiliative, $\mathrm{SE}=$ self-enhancing, $\mathrm{AG}=$ aggressive, $\mathrm{SD}=$ self-defeating.

\section{References}

DeNeve, K. M. \& Cooper, H. (1998). 'The happy personality: A meta-analysis of 137 personality traits and subjective well-being'. Psychological Bulletin, 124, pp. 197-229. doi:10.1037/0033-2909.124.2.197 
Diener, E. D., Emmons, R. A., Larsen, R. J., \& Griffin, S. (1985). 'The satisfaction with life scale'. Journal of Personality Assessment, 49, pp. 71-75. doi:10.1207/s15327752jpa4901_13Digman, J. M. (1990). 'Personality structure: Emergence of the five-factor model'. In M. R. Rosenzweig \& L. W. Porter (Eds.), Annual review of psychology (Vol. 41, pp. 417-440). Palo Alto, CA: Annual Reviews.

Dyck, K. T. H. \& Holtzman, S. (2013). 'Understanding humor styles and well-being: The importance of social relationships and gender'. Personality and Individual Differences, 55, pp. 53-58. doi:10.1016/j.paid.2013.01.023

Edwards, K. R. \& Martin, R. A. (2010). 'Humor creation ability and mental health: Are funny people more psychologically healthy?' Europe's Journal of Psychology, 6, pp. 196-212. doi:10.5964/ejop.v6i3.213

Eysenck, S. B., Eysenck, H. J. \& Barrett, P. (1985). 'A revised version of the Psychoticism scale'. Personality and Individual Differences, 6(1), pp. 21-29. doi:10.1016/01918869(85)90026-1

Freud, S. (1905): Der Witz und seine Beziehungen zum Unbewußten [Jokes and their relation to the unconscious]. Vienna, Austria: Deuticke.

Frewen, P. A., Brinker, J., Martin, R. A. \& Dozois, D. J. A. (2008). 'Humor styles and personality vulnerability to depression'. Humor: International Journal of Humor Research, 21, pp. 179-195. doi:10.1515/HUMOR.2008.009

Galloway, G. (2010). 'Individual differences in personal humor styles: Identification of prominent patterns and their associates'. Personality and Individual Differences, 48, pp. 563-567. doi:10.1016/j.paid.2009.12.007

John, O. P., Donahue, E. M., \& Kentle, R. L. (1991). The big five inventory-versions $4 a$ and 54. Berkeley: University of California, Berkeley, Institute of Personality and Social Research.

Jovanovic, V. (2011). 'Do humor styles matter in the relationship between personality and subjective well-being?' Scandinavian Journal of Psychology, 52, pp. 502-507. doi:10.1111/j.1467-9450.2011.00898.x

Köhler, G. \& Ruch, W. (1996). 'Sources of variance in current sense of humor inventories: How much substance, how much method variance?' Humor: International Journal of Humor Research, 9, pp. 363-397. doi:10.1515/humr.1996.9.3-4.363

Kuiper, N. A., Grimshaw, M., Leite, C. \& Kirsh, G. (2004). 'Humor is not always the best medicine: Specific components of sense of humor and psychological well-being'. Humor: International Journal of Humor Research, 17, pp. 135-168. doi:10.1515/humr.2004.002

Kuiper, N. A. \& Harris, A. L. (2009). 'Humor styles and negative affect as predictors of different components of physical health'. Europe's Journal of Psychology, 5(1). doi:10.5964/ejop.v5i1.280

Martin, R. A. (1996). 'The Situational Humor Response Questionnaire (SHRQ) and Coping Humor Scale (CHS): A decade of research findings'. Humor: International Journal of Humor Research, 9, pp. 251-272. doi:10.1515/humr.1996.9.3-4.251

Martin, R. A. (2001). 'Humor, laughter, and physical health: Methodological issues and research findings'. Psychological Bulletin, 127, pp. 504-519. doi:10.1037/00332909.127.4.504

Martin Rod, A. (2007). The psychology of humor. An intergrative approach. Burlington, MA: Elsevier Academic Press.

Martin, R. A. \& Lefcourt, H. M. (1983). 'Sense of humor as a moderator of the relation between stressors and moods'. Journal of Personality and Social Psychology, 45, pp. 1313-1324. doi:10.1037/0022-3514.45.6.1313 
Martin, R. A., Puhlik-Doris, P., Larsen, G., Gray, J. \& Weir, K. (2003). 'Individual differences in uses of humor and their relation to psychological well-being: Development of the Humor Styles Questionnaire'. Journal of Research in Personality, 37, pp. 48-75. doi:10.1016/S0092-6566(02)00534-2

McGhee, P. E. (1999). The laughter remedy. Health, healing and the amuse system. Dubuque, IA: Kendall/Hunt.

Páez, D., Mendiburo, A. \& Martínez-Sanchez, F. (2013). 'Incremental validity of alexithymia, emotional coping and humor style on happiness and psychological well-being'. Journal of Happiness Studies, 14, pp. 1621-1637. doi:10.1007/s10902-012-9400-0

Proyer, R. T. (2012). 'Development and initial assessment of a short measure for adult playfulness: The SMAP'. Personality and Individual Differences, 53, pp. 989-994. doi:10.1016/j.paid.2012.07.018

Proyer, R. T., Ruch, W. \& Müller, L. (2010). 'Sense of humor among the elderly: Findings with the German version of the SHS'. Zeitschrift für Gerontologie und Geriatrie, 43, pp. 19-24. doi:10.1007/s00391-009-0082-0

Radloff, L. S. (1977). 'The CES-D scale: A self-report depression scale for research in the general population'. Applied Psychological Measurement, 1, pp. 385-401. doi:10.1177/014662167700100306.

Robins, R. W., Tracy, J. L. Trzesniewski, K. H., Potter, J. \& Gosling, S. D. (2001). 'Personality correlates of self-esteem'. Journal of Research in Personality, 35, pp. 463482. doi:10.1006/jrpe.2001.2324

Rosenberg, M. (1965). Society and the adolescent self-image. Princeton, NJ: Princeton University Press.

Ruch, W. \& Heintz, S. (2014). Separating content and context in questionnaire items: How much substance, how much noise? Unpublished manuscript. Department of Psychology, University of Zurich.

Ruch, W., Heintz, S. \& Auerbach, A. (2012). Item statistics of the revised SHS. Unpublished data. Department of Psychology, University of Zurich.

Saroglou, V. \& Scariot, C. (2002). 'Humor Styles Questionnaire: Personality and educational correlates in Belgian high school and college students'. European Journal of Personality, 16, pp. 43-54. doi:10.1002/per.430

Scheier, M. F., Carver, C. S., \& Bridges, M. W. (1994). 'Distinguishing optimism from neuroticism (and trait anxiety, self-mastery, and self-esteem): A reevaluation of the Life Orientation Test'. Journal of Personality and Social Psychology, 67, pp. 1063-1078. doi:10.1037/0022-3514.67.6.1063

Sharpe, J. P., Martin, N. R. \& Roth, K. A. (2011). 'Optimism and the Big Five factors of personality: Beyond neuroticism and extraversion'. Personality and Individual Differences,51, pp. 946-951. doi:10.1016/j.paid.2011.07.033

von Collani, G. \& Herzberg, P. Y. (2003). 'Eine revidierte Fassung der deutschsprachigen Skala zum Selbstwertgefühl von Rosenberg [A revised version of the German adaptation of Rosenberg's self-esteem scale]'. Zeitschrift für Differentielle und Diagnostische Psychologie, 24, pp. 3-7. doi:10.1024//0170-1789.24.1.3

Watson, D., Clark, L. A. \& Tellegen, A. (1988). 'Development and validation of brief measures of positive and negative affect: The PANAS scales'. Journal of Personality and Social Psychology, 54, pp. 1063-1070. doi:10.1037/0022-3514.54.6.1063. 